\title{
Structural behaviour and strain distribution of the long bones of the human lower limbs
}

\author{
Luca Cristofolini $^{\mathrm{a}, \mathrm{b}, *}$, Giorgia Conti ${ }^{\mathrm{a}, \mathrm{b}}$, Mateusz Juszczyk ${ }^{\mathrm{a}, \mathrm{b}}$, Sara Cremonini ${ }^{\mathrm{a}}$, Serge Van Sint Jan ${ }^{\mathrm{c}}$, \\ Marco Viceconti ${ }^{\text {a }}$ \\ a Laboratorio di Tecnologia Medica, Istituto Ortopedico Rizzoli, Via di Barbiano, 1/10, 40136 Bologna, Italy \\ ${ }^{\mathrm{b}}$ Facoltà di Ingegneria, Università di Bologna, Italy \\ ${ }^{\mathrm{c}}$ Laboratory of Anatomy, Biomechanics and Organogenesis, Université Libre de Bruxelles, Belgium
}

\section{A R T I C L E I N F O}

Article history:

Accepted 20 November 2009

\section{Keywords:}

Lower limb bones

Strain distribution

Structural stiffness

Femur

Tibia

Fibula

In vitro biomechanical testing

\begin{abstract}
A B S T R A C T
Although stiffness and strength of lower limb bones have been investigated in the past, information is not complete. While the femur has been extensively investigated, little information is available about the strain distribution in the tibia, and the fibula has not been tested in vitro. This study aimed at improving the understanding of the biomechanics of lower limb bones by: (i) measuring the stiffness and strain distributions of the different low limb bones; (ii) assessing the effect of viscoelasticity in whole bones within a physiological range of strain-rates; (iii) assessing the difference in the behaviour in relation to opposite directions of bending and torsion. The structural stiffness and strain distribution of paired femurs, tibias and fibulas from two donors were measured. Each region investigated of each bone was instrumented with 8-16 triaxial strain gauges (over 600 grids in total). Each bone was subjected to 6-12 different loading configurations. Tests were replicated at two different loading speeds covering the physiological range of strain-rates. Viscoelasticity did not have any pronounced effect on the structural stiffness and strain distribution, in the physiological range of loading rates explored in this study. The stiffness and strain distribution varied greatly between bone segments, but also between directions of loading. Different stiffness and strain distributions were observed when opposite directions of torque or opposite directions of bending (in the same plane) were applied. To our knowledge, this study represents the most extensive collection of whole-bone biomechanical properties of lower limb bones.
\end{abstract}

(c) 2009 Elsevier Ltd. All rights reserved.

\section{Introduction}

Measuring the stiffness, strength and strain distribution of bones is extremely important to understand bone biomechanics (Fung, 1980), bone formation and adaptation (Lanyon, 1980; Fung, 1990), osteoporosis (NIH, 2000), and fractures (Rockwood et al.,1991).

In some cases a theoretical approach was taken to explain the structural stiffness of the femur, exploiting straight (Toridis, 1969; Cristofolini et al., 1996a) or curved beam theory (Raftopoulos and Qassem, 1987; Fabeck et al., 2002). However, such simplified approach cannot be used to investigate subtle effects. (Martens et al., 1980) measured in vitro the torsional stiffness and strength of 46 femurs and 37 tibias (however, specimens were not tested in pairs, and only some of the femurs and tibias came from the same

\footnotetext{
* Corresponding author at: Laboratorio di Tecnologia Medica, Istituto Ortopedico Rizzoli, Via di Barbiano, 1/10, 40136 Bologna, Italy. Tel.: +39051 6366864; fax: + 390516366863 .

E-mail addresses: cristofolini@tecno.ior.it, tecno@tecno.ior.it (L. Cristofolini).
}

donor). Later, (Martens et al., 1986) tested to failure 15 pairs of femurs in bending. Failure of the proximal femoral metaphysis has often been investigated in vitro (e.g.Yang et al., 1996; Lochmüller et al., 2002; Cristofolini et al., 2007). In all such studies, only structural properties were investigated, while the strain distribution was not measured. When the strain distribution was investigated in the femur, in most cases a single loading configuration was used (e.g. Field and Rushton, 1989). A very detailed study on femur strains, although limited to a single specimen, is (Huiskes et al., 1981): they applied different loading configurations to a human femur instrumented with 100 strain gauges. Later, (Cristofolini et al., 2009) measured strains in 12 pairs of human femurs (11 strain gauges in the proximal metaphysis), with 6 different loading configurations. Also, the strain distribution in the tibia has sometimes been measured (Gray et al., 2008).

Viscoelasticity of bone tissue has been demonstrated at the tissue-level (Lakes and Katz, 1979). The Young modulus increases by $10 \%$ when the strain-rate is increased by 3 orders of magnitude (Raftopoulos et al., 1993). Most creep takes place in the first seconds, and accounts for typically $5-10 \%$ of the strain immediately after load application (Sasaki et al., 1993). However, due to 
the limited viscoelasticity of bone, elastic models are often used to describe cortical (Carter and Spengler, 1978; Fung, 1980) and cancellous bone (Martens et al., 1983; Keaveny et al., 1994). In fact, when cancellous bone was tested at different rates, viscoelasticity became obvious only at very low strain-rates (Guedes et al., 2006). When whole bones are investigated, the practical effects of viscoelasticity are questionable (CherrafSchweyer et al., 2007). For instance, Cristofolini et al. (2009) showed that creep over 30 seconds. (most physiological motor tasks take place in a shorter timespan) accounts for only $0.1-3.0 \%$ of the initial strain value. In fact, in most Finite Element (FE) models, bone is modelled as a linear material (Helgason et al., 2008). Only recently strain-rate-dependent material properties were implemented in FE models (Helgason et al., 2008).

This review shows some limitations of the current knowledge. Firstly, while the structural behaviour and strain distribution in the femur has been extensively studied (e.g. (Huiskes et al., 1981; Field and Rushton, 1989; Yang et al., 1996; Lochmüller et al., 2002; Cristofolini et al., 2007; Cristofolini et al., 2009)), limited information is available for the tibia: the stiffness was measured in several specimens (Martens et al., 1980; Cristofolini and Viceconti, 2000; Heiner and Brown, 2001), but the strain distribution was measured only proximally (Gray et al., 2008). To our knowledge, no biomechanical properties have been measured for the fibula. Moreover, most of the published studies on lower limb bones focus on single bones, not on entire sets of bones from the same donors. In addition, the practical effect of viscoelasticity on the structural behaviour and strain distribution of whole bones is unclear. It is not ascertained whether different loading rates within the physiological range cause a different response, and if a linear and symmetric mechanical behaviour should be expected in long bones.

The aims of the present study were to:

- Measure the stiffness and strain distributions of the different low limb bones from the same donors;

- assess if there is any significant effect of viscoelasticity on the structural behaviour and strain distribution in whole bones for physiological strain-rates;

- assess if the structure and material properties cause any difference in relation to the direction of the applied load, especially considering opposite directions of bending and torsion.

\section{Materials and methods}

The structural stiffness and strain distribution of the proximal metaphysis and the diaphysis of the femur, and the diaphysis of the tibia and fibula were investigated.
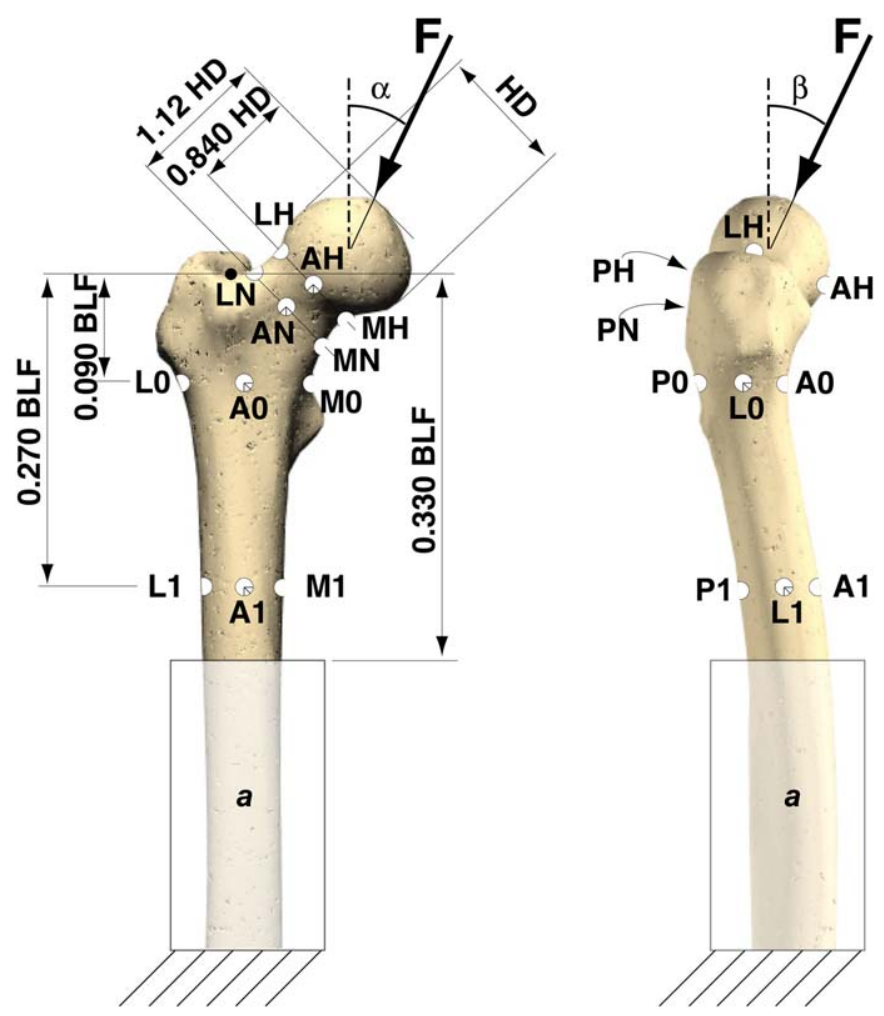

Fig. 1. Anterior and lateral views of the proximal metaphysis of a right femur. The position of the strain gauges is reported: 4 around the head, close to the articular cartilage ( $\mathrm{AH}, \mathrm{LH}, \mathrm{PH}, \mathrm{MH}) ; 4$ around the neck, distal to the previous ones (AN, $\mathrm{LN}$, $\mathrm{PN}, \mathrm{MN}$ : space on the lateral side was insufficient to host one additional strain gauge); 4 around the proximal diaphysis, just below the lesser trochanter (A0, L0, P0, M0); 4 around the proximal part of diaphysis (A1, L1, P1, M1: they were the same as in the femoral diaphysis, Fig. 2). To enable scaling between specimens, all lengths were defined as a fraction of the head diameter (HD) or of the biomechanical length of the femur (BLF, defined in Fig. 2). The femur was held distally using a pot made of acrylic bone cement (a). The pot could be tilted so that the hip joint resultant force $(F)$ was applied at the prescribed angles in the frontal plane $(\alpha)$, and in the sagittal plane $(\beta)$, as in Cristofolini et al. (2009).

Table 1

Details of the donors.

\begin{tabular}{|c|c|c|c|c|c|}
\hline & Age at death (years) & Donors' height (cm) & Donors' body weight, BW (kg) & Body mass index, BMI $\left(\mathrm{kg} / \mathrm{m}^{2}\right)$ & Gender \\
\hline Donor \#1 & 81 & 165 & 63 & 23.1 & Female \\
\hline Donor \#2 & 78 & 171 & 64 & 21.9 & Female \\
\hline
\end{tabular}

Table 2

Anatomical details of the bone specimens analyzed.

\begin{tabular}{|c|c|c|c|c|c|c|}
\hline & \multicolumn{4}{|l|}{ Femur } & \multirow{2}{*}{\multicolumn{2}{|c|}{$\begin{array}{l}\text { Tibia and fibula } \\
\text { Biomechanical length, BLT (mm) }\end{array}$}} \\
\hline & \multicolumn{2}{|c|}{ Head diameter, HD (mm) } & \multicolumn{2}{|c|}{ Biomechanical length, BLF (mm) } & & \\
\hline & Right & Left & Right & Left & Right & Left \\
\hline Donor \#1 & 47.5 & 47.5 & 427 & 427 & 362 & 364 \\
\hline Donor \#2 & 46.5 & 47.8 & 415 & 412 & 351 & 346 \\
\hline
\end{tabular}

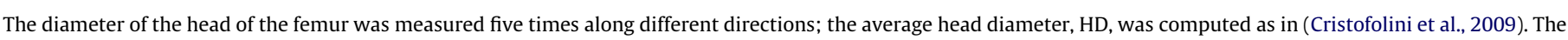

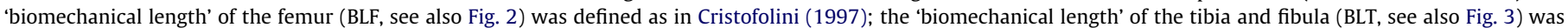
defined as in Conti et al. (2008). 


\subsection{Specimens}

Paired femurs, tibias and fibulas were obtained from two donors, who neither suffered from cancer nor skeletal diseases (Table 1). All 12 bones were CT-scanned to exclude fractures or other defects. Bones were embalmed (Ohman et al., 2008), and hydration was preserved during tests using moistened cloths. Anatomical reference frames were marked and dimensions were measured on each bone (Cristofolini (1997) for the femur and Conti et al. (2008) for the tibia and fibula; Table 2).

\subsection{Strain measurement}

Each bone segment was instrumented with triaxial-stacked strain gauges following a validated procedure (Cristofolini et al., 2009):

- Proximal femoral metaphysis: 16 strain gauges (KFG-1-120-D17-23L3M2S, Kyowa, Tokyo, Japan, grid length=1 mm) (Fig. 1) (Cristofolini et al., 2009);

- femoral diaphysis: 16 strain gauges (KFW-2-350-D17-23L2M2S, Kyowa, length=2 mm) (Fig. 2);

- tibial diaphysis: 15 strain gauges (KFW-2-350-D17-23L2M2S, Kyowa, length=2 mm) (Fig. 3);

- fibular diaphysis: 8 strain gauges (KFG-1-120-D17-23L3M2S, Kyowa, length=1 $\mathrm{mm}$ ) (Fig. 4).

A grid excitation of $0.5 \mathrm{~V}$ was selected to avoid heating. Strains and loaddisplacement data from the testing machine were sampled at $2000-5000 \mathrm{~Hz}$ (depending on the strain-rate-see below), using a 60-channel data logger (System-6000, Vishay Micro-Measurement, Raleigh, NC, USA). Principal strains were computed based on the three grids of each strain gauge.

\subsection{In vitro loading}

An axial-torsional servo-hydraulic machine (858-MiniBionix, MTS, Minneapolis, USA) was used. For each type of loading, suitable loading setups were designed (using hinges and universal joints) that avoided any additional load components.
To investigate the strain distribution in the proximal femoral metaphysis, a single force was applied to the femoral head at different directions, simulating the hip joint resultant force (Fig. 1 (Cristofolini et al., 2009)). Muscle forces were not simulated, as they do not significantly alter the stress distribution in the proximal metaphysic (Cody et al., 1999; Keyak et al., 2005; Cristofolini et al., 2007,2009 ). Four configurations were designed to cover the physiological range of loading directions during a variety of activities (Bergmann et al., 2001). The cone spanned by the hip joint resultant force was calculated: LC1-LC4 (Table 3) corresponded to the extreme angles of the resultant force in the frontal and sagittal planes (Taddei et al., 2006; Cristofolini et al., 2009). To replicate a loading configuration used in the literature to replicate simplified single-leg stance, the hip joint force was applied parallel to the femoral diaphysis (LC5, Table 3). The last configuration (LC6, Table 3) has been proposed to in vitro replicate spontaneous fractures of the proximal femur (i.e. not associated with any primary trauma, but due to sudden application of para-physiological load peaks (Cristofolini et al., 2007)).

Four-point-bending of the diaphysis of the femur, tibia and fibula was consistent with Cristofolini et al. (1996a, 1996b), Cristofolini and Viceconti (2000), Heiner and Brown (2001) and Gray et al. (2008): equally spaced rollers generated bending either in the frontal plane or sagittal plane (Figs. 2-4). Deflection at the mid-point was measured by a single-arm extensometer $(632.06 \mathrm{H}-20, \mathrm{MTS})$. Bending in each plane was exerted in both opposite directions to assess if a difference existed (Table 3). Bending stiffness was defined as the average slope of the force-deflection curve between $10 \%$ and $90 \%$ of the full load.

Torsional testing of the diaphysis of the femur, tibia and fibula was consistent with Cristofolini et al. (1996a, 1996b), Cristofolini and Viceconti (2000), Heiner and Brown (2001) and Gray et al. (2008): rotation was recorded while the testing machine applied a controlled torque to the extremities of the diaphysis. Torsion was exerted in both opposite directions to assess if a difference existed (Table 3 ). Torsional stiffness was defined as the average slope of the torque-rotation curve between $10 \%$ and $90 \%$ of the full load.

To avoid damage during repeated loading, the failure load for each configuration was estimated with preliminary FE models, using a validated procedure (Schileo et al., 2007, 2008). The full load applied in vitro was approximately $10 \%$ of estimated failure load (for consistency, load was scaled between donors based on Body Weight, BW, Table 3).
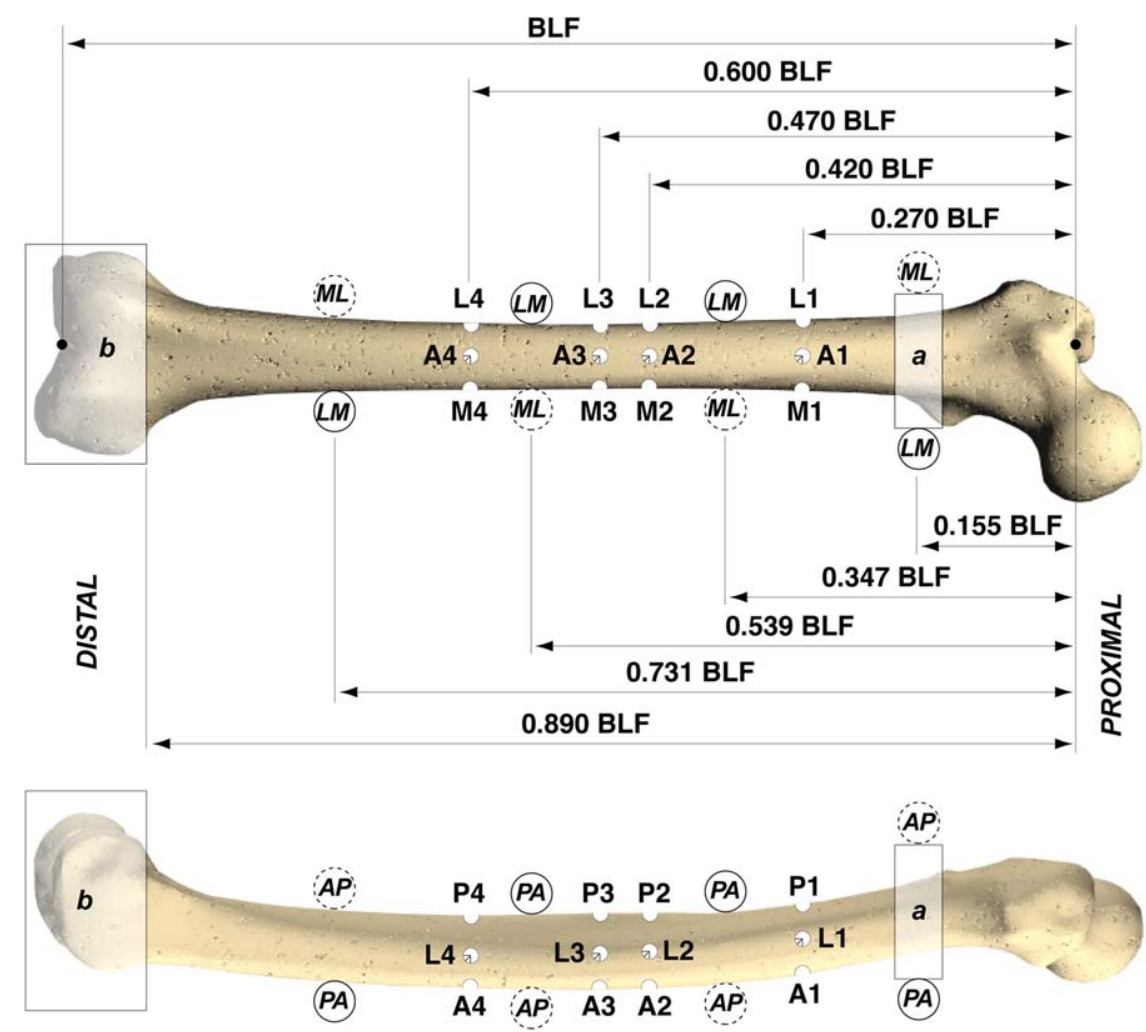

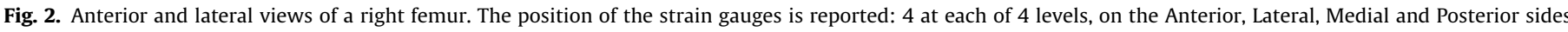

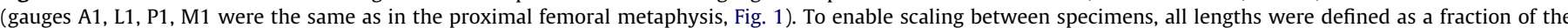

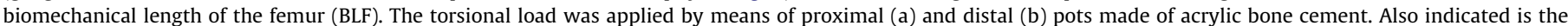

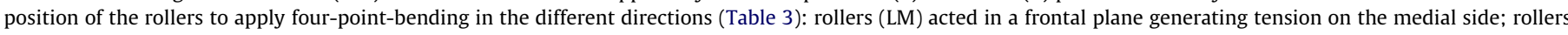

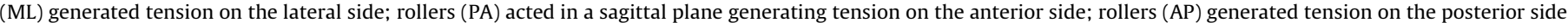
(AP). The most proximal rollers always rested on the flat faces of pot (a) to prevent the specimen from rotating axially. 

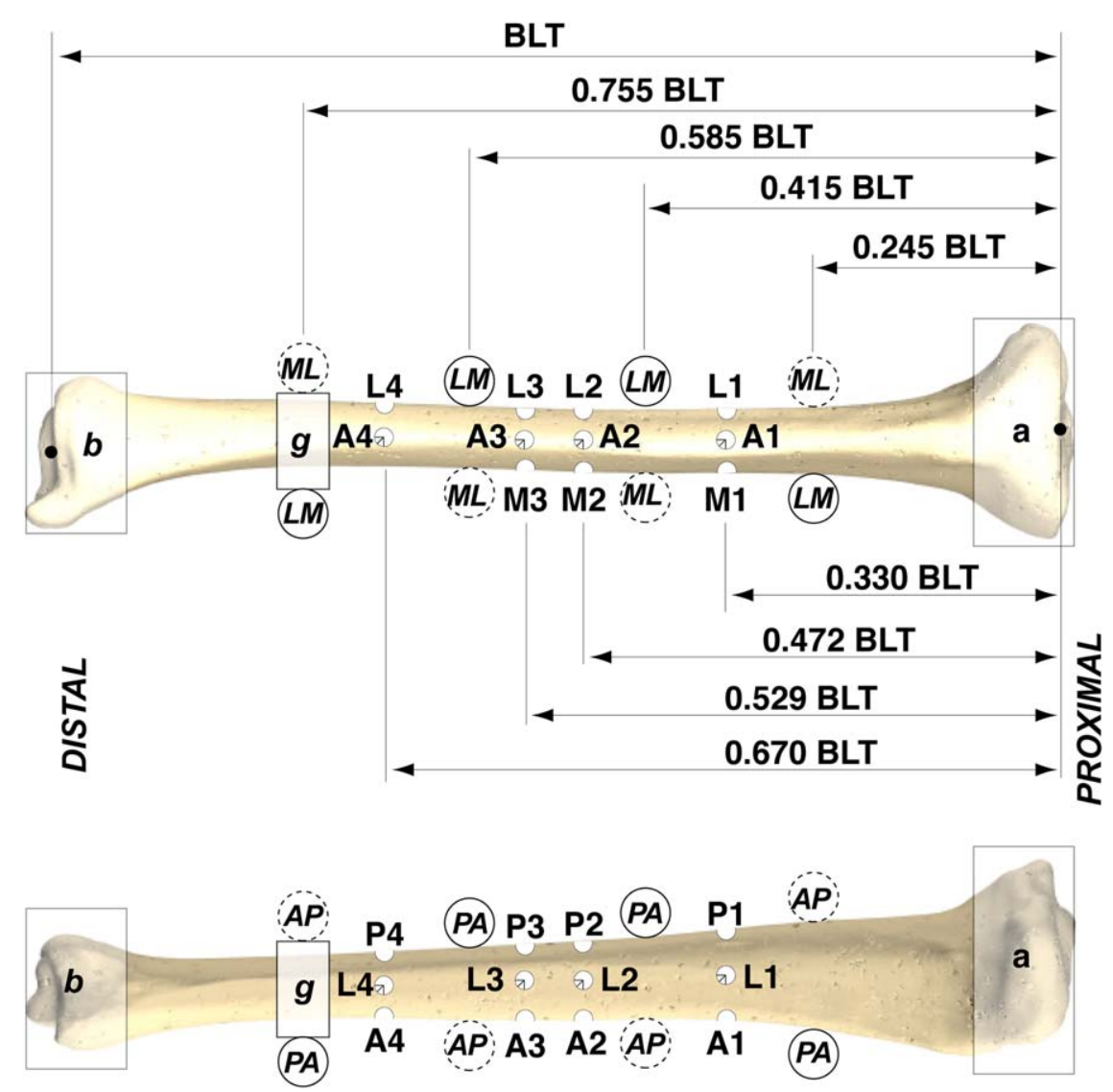

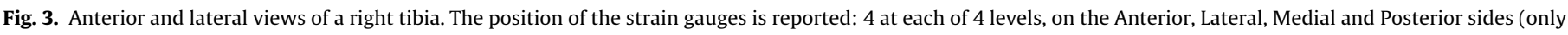

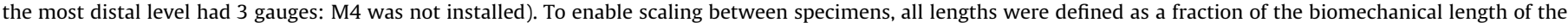

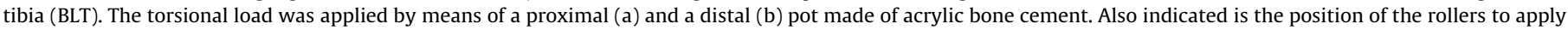

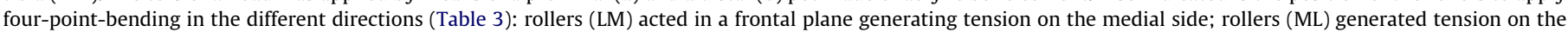

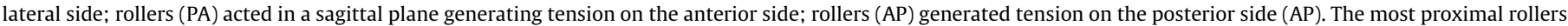
always rested on the flat faces of pot $(\mathrm{g})$ to prevent the specimen from rotating axially.
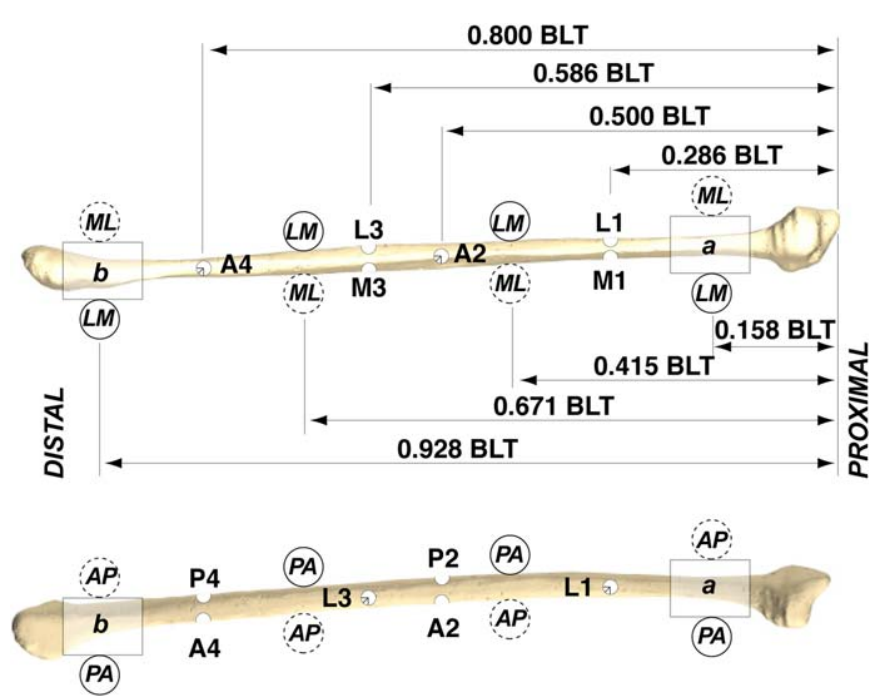

Fig. 4. Anterior and lateral views of a right fibula. The position of the strain gauges is reported: 2 at each of 4 levels (either Anterior and Posterior, or Lateral and Medial). To enable scaling between specimens, all lengths were defined as a fraction of the biomechanical length (BLT). The torsional load was applied by means of a proximal (a) and a distal (b) pot made of acrylic bone cement. Also indicated is the position of the rollers to apply four-point-bending in the different directions (Table 3): rollers (LM) acted in a frontal plane generating tension on the medial side; rollers (ML) generated tension on the lateral side; rollers (PA) acted in a sagittal plane generating tension on the anterior side; rollers (AP) generated tension on the posterior side (AP). The most proximal rollers always rested on the flat faces of pot (a) to prevent the specimen from rotating axially.
To cover the range of physiological strain-rates, load was applied at different speeds:

- High-strain-rate: the load ramp was tuned so that the strain-rate in the most stressed regions was $0.05 \mathrm{~s}^{-1}$. As bone tissue fails when strain exceeds 0.007-0.010 (Bayraktar et al., 2004), such strain-rate would generate failure in the order of $0.2 \mathrm{~s}$. This is the typical timescale of physiological and para-physiological loading (Bergmann et al., 2001, 2004), and has been proposed in the past for in vitro testing (Raftopoulos et al., 1993);

- low-strain-rate: a strain-rate ten times lower than high-strain-rate was implemented to replicate quasi-static loading events, consistently with Bergmann et al. (2001);

- for both strain-rates, the maximum load was held for $2 \mathrm{~s}$ before unloading to enable accurate strain recording.

Each loading configuration was tested six times on each specimen, dismounting and realigning the entire loading setup between repetitions ( $3 \mathrm{~min}$ recovery between repetitions).

\subsection{Statistical analysis}

Linearity between force and strain was checked by linear regression separately for each strain gauge and each specimen.

Preliminarily, differences between the two donors were examined. Differences between donors were sometimes larger than $50 \%$ for the stiffness, and $100 \%$ for the strain (Factorial ANOVA, $p<0.0005$ ). Therefore, the two donors were analyzed separately.

To assess the effect on the bone stiffness of the loading direction and loading rate, a factorial ANOVA was performed separately for the two donors and for each bone segment (femur, tibia, fibula). The following independent factors 
Table 3

Details of the loading configurations applied to the femur, tibia and fibula: direction and magnitude of applied loads.

\begin{tabular}{|c|c|c|c|c|}
\hline & Direction of applied load & Femur & Tibia & Fibula \\
\hline $\begin{array}{l}\text { Proximal } \\
\text { metaphysis }\end{array}$ & $\begin{array}{l}\text { Direction of applied force ( } \alpha \text { and } \beta \text { defined inFig. 1): } \\
\text { LC1: Max flexion: } \alpha=0^{\circ}, \beta=+18^{\circ} \\
\text { LC2: Max abduction: } \alpha=+3^{\circ}, \beta=0^{\circ} \\
\text { LC3: Max extension: } \alpha=0^{\circ}, \beta=-3^{\circ} \\
\text { LC4: Max adduction: } \alpha=+24^{\circ}, \beta=0^{\circ} \\
\text { LC5: Neutral: } \alpha=0^{\circ}, \beta=0^{\circ} \\
\text { LC6: Simulated failure: } \alpha=+8^{\circ}, \beta=0^{\circ}\end{array}$ & Applied force: $0.75 \mathrm{BW}$ & Not tested & Not tested \\
\hline $\begin{array}{l}\text { Four-point- } \\
\text { bending }\end{array}$ & $\begin{array}{l}\text { Direction of applied flexion: } \\
\text { AP: bending in sagittal plane (tension on posterior side) } \\
\text { PA: bending in sagittal plane (tension on anterior side) } \\
\text { ML: bending in frontal plane (tension on lateral side) } \\
\text { LM: bending in frontal plane (tension on medial side) }\end{array}$ & $\begin{array}{l}\text { Force applied at each } \\
\text { roller: } 0.563 \mathrm{BW}\end{array}$ & $\begin{array}{l}\text { Force applied at each } \\
\text { roller: } 0.243 \mathrm{BW}\end{array}$ & $\begin{array}{l}\text { Force applied at each } \\
\text { roller: } 0.0324 \mathrm{BW}\end{array}$ \\
\hline Torsion & $\begin{array}{l}\text { Direction of applied torque: } \\
\text { INTRA: torque causing intra-rotation of the distal } \\
\text { extremity } \\
\text { EXTRA: torque causing extra-rotation of the distal } \\
\text { extremity }\end{array}$ & $\begin{array}{l}\text { Applied torque: } \\
42.1 \mathrm{BW} \mathrm{mm}\end{array}$ & $\begin{array}{l}\text { Applied torque: } \\
11.9 \mathrm{BW} \mathrm{mm}\end{array}$ & $\begin{array}{l}\text { Applied torque: } \\
0.985 \text { BW mm }\end{array}$ \\
\hline
\end{tabular}
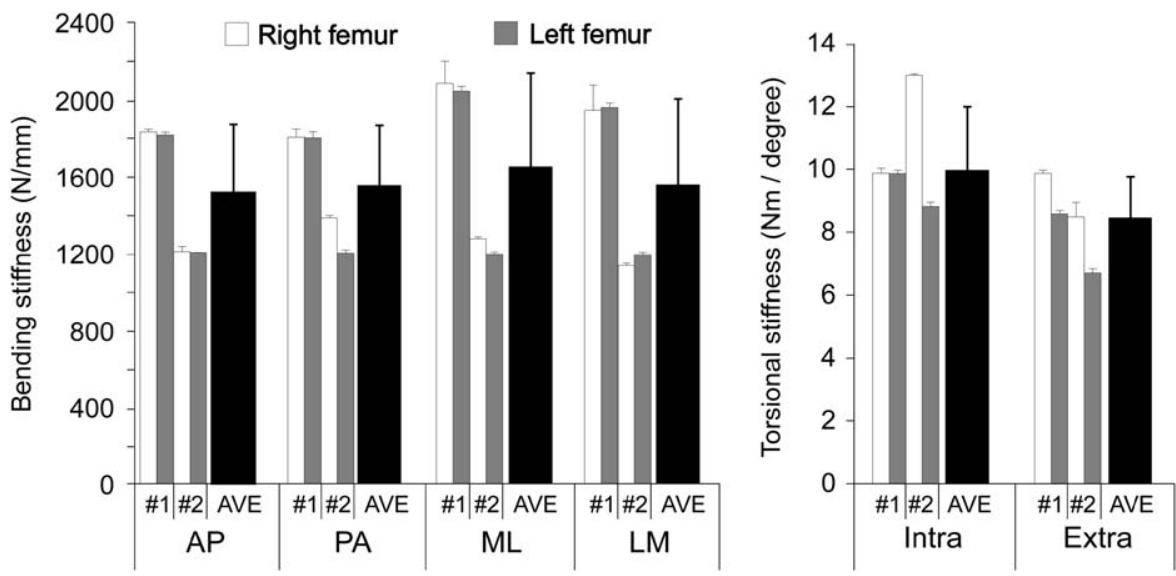

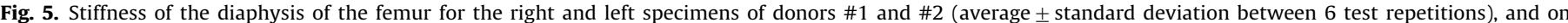

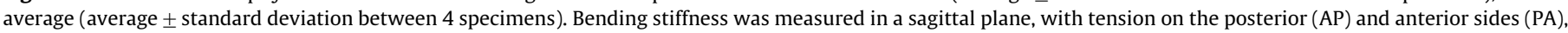

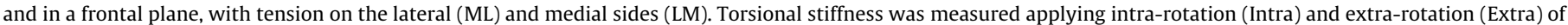
the distal extremity. Data represented here correspond to the low-strain-rate; similar trends were observed for the high-strain-rate.

were examined:

- Donor's side (right, left);

- loading configuration (6 configurations for the proximal metaphysis, 4 for four-point-bending, 2 for torsion);

- loading speed (high-strain-rate, low-strain-rate).

A similar analysis was performed also on the strain distribution, where the strain measurement location was included as an additional factor. When applicable, the test of Scheffé was applied for post-hoc pair-wise comparisons.

To visualize the effect of opposite directions of loading (e.g. intra-rotation vs. extra-rotation) on the strain distribution, the correlation between the strains measured with opposite directions of applied load was investigated by means of linear regression. To visualize the effect of the loading rate on the strain distribution, the correlation between the strain measured at high-strain-rate and low-strain-rate was investigated by means of linear regression.

\section{Results}

\subsection{Linearity and creep}

Linearity between load and displacement was excellent $\left(R^{2} \geq 0.98\right)$. Also load-strain and displacement-strain linearity was excellent $\left(R^{2} \geq 0.97\right.$ at all strain measurement locations where strain exceeded 100 microstrain).

Strain magnitude tended to increase over time by typically $0.1-3.0 \%$ of the initial value while load was held (for $2 \mathrm{~s}$ ). After unloading, strain returned rapidly to zero, with residual strain ( 3 min after unloading) of $0.5-4 \%$ of the peak value.

Strain repeatability (intra-specimen variability) was good: the Coefficient of Variation between replicates under the same conditions was on average $0.4 \%$ for the proximal femoral metaphysis, $2.5 \%$ for four-point-bending, and $0.5 \%$ for torsion.

\subsection{Stiffness and strain distribution}

The femurs were slightly stiffer than the tibias for all directions of loading (Figs. 5 and 6 ) The fibulas were $1-2$ orders of magnitude less stiff than the femurs and tibias (Figs. 5-7). Principal strain was generally aligned with the long axis of the diaphysis in bending (with tensile and compressive strain depending on the direction of bending), and roughly at $45^{\circ}$ in 

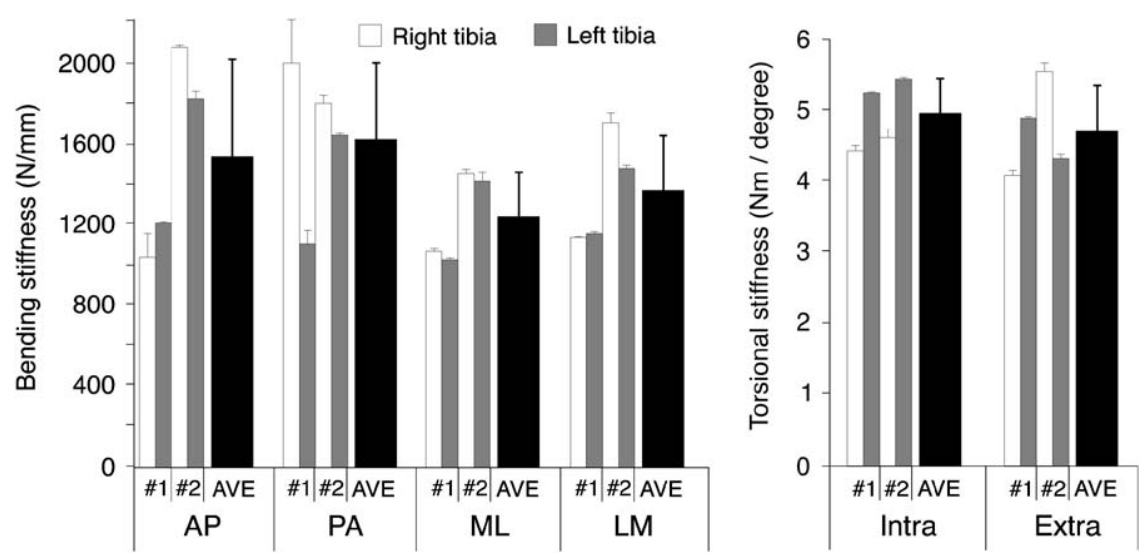

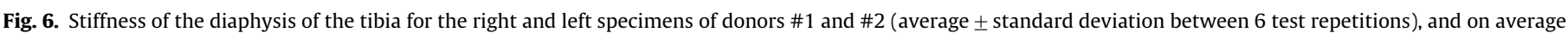

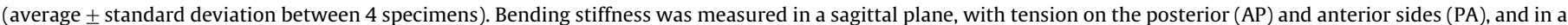

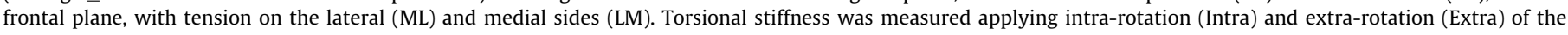
distal extremity. Data represented here correspond to the low-strain-rate; similar trends were observed for the high-strain-rate.
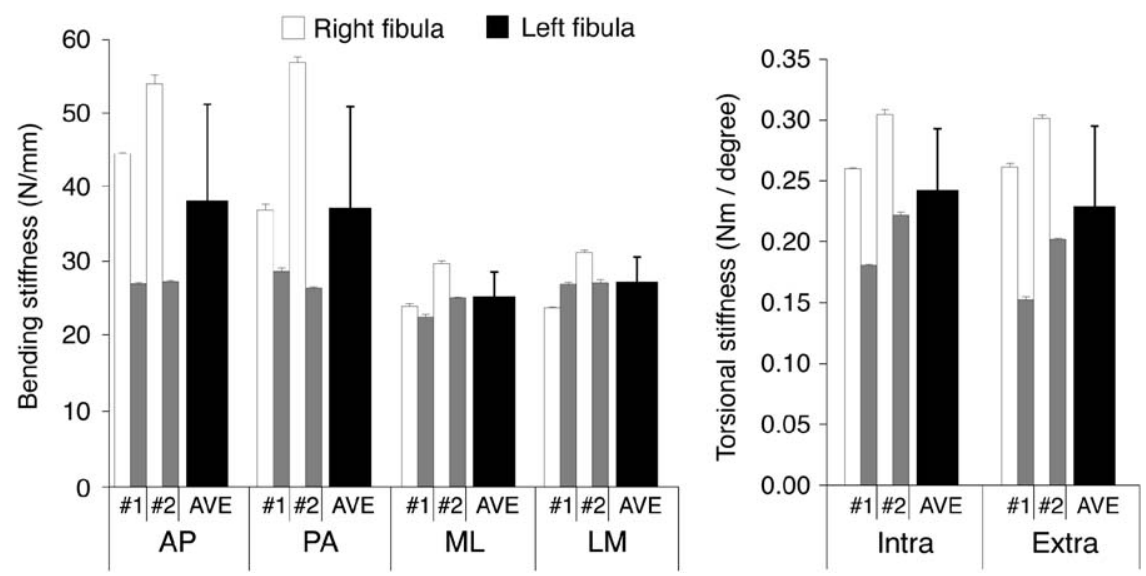

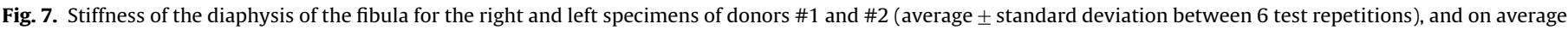

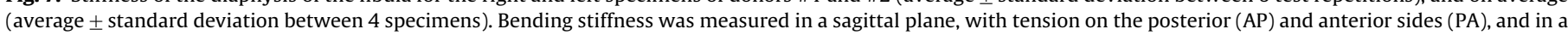

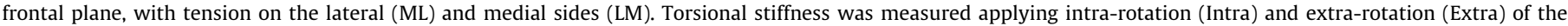
distal extremity. Data represented here correspond to the low-strain-rate; similar trends were observed for the high-strain-rate.

Table 4

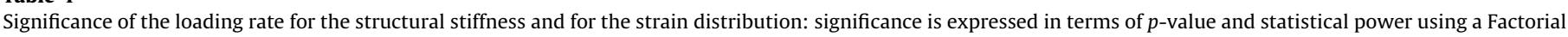
ANOVA.

\begin{tabular}{|c|c|c|c|}
\hline & Femur & Tibia & Fibula \\
\hline Proximal metaphysis & $\begin{array}{l}\text { Lower strain at high-strain-rate } \\
(p=0.1 \text {, power }=0.4)\end{array}$ & Not tested & Not tested \\
\hline Diaphysis: four-point-bending & $\begin{array}{l}2 \% \text { less stiff at high-strain-rate } \\
(p>0.1, \text { power }=0.3) \\
\text { Lower strain at high-strain-rate } \\
(p<0.1 \text {, power }=0.1)\end{array}$ & $\begin{array}{l}\text { 1\% less stiff at high-strain-rate } \\
(p>0.1, \text { power }=0.1) \\
\text { Similar strain at both strain-rates } \\
(p=0.1, \text { power }=0.4)\end{array}$ & $\begin{array}{l}16 \% \text { stiffer at high-strain-rate } \\
(p<0.005) \\
\text { Similar strain at both strain-rates } \\
(p=0.1, \text { power }=0.5)\end{array}$ \\
\hline Diaphysis: torsion & $\begin{array}{l}4 \% \text { stiffer at high-strain-rate } \\
(p<0.005) \\
\text { Lower strain at high-strain-rate } \\
(p<0.1 \text {, power }=0.1)\end{array}$ & $\begin{array}{l}6 \% \text { stiffer at high-strain-rate } \\
(p<0.01) \\
\text { Similar strain at both strain-rates } \\
(p=0.1, \text { power }=0.4)\end{array}$ & $\begin{array}{l}0.1 \% \text { less stiff at high-strain-rate } \\
(p>0.5 \text {, power }=0.1) \\
\text { Similar strain at both strain-rates } \\
(p=0.1 \text {, power }=0.5)\end{array}$ \\
\hline
\end{tabular}

As the two donors were analyzed separately (with different results in absolute terms, but similar trends), upper/lower bounds are reported for the $p$-values.

torsion. The strain magnitude depended significantly on the strain measurement location (Factorial ANOVA, $p<0.0005$, in all bone segments). For space reasons, details about the strain distribution are not reported here. Full strain maps for the different loading configurations are available from the Journal website. The entire multi-scale collection of biomechanical properties for the skeletons of such donors is found in the Living Human Digital Library (LHDL) repository in PhysiomeSpace 
(https://www.biomedtown.org/biomed_town/LHDL/users/ repository/-access free to registered individuals affiliated to research institutions).

\subsection{Effect of loading rate}

The loading rate had a small and somewhat jeopardized effect on the structural stiffness of the diaphysis: when this effect was statistically significant, the bones behaved in a stiffer way at the high-strain-rate (Table 4).

a

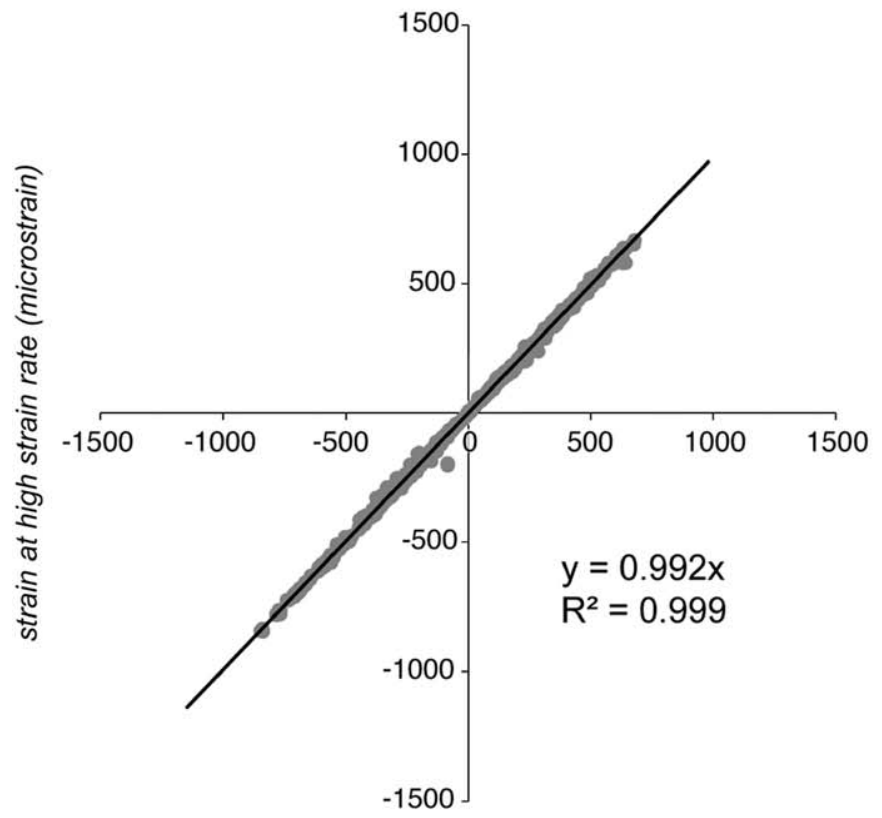

strain at low strain rate (microstrain)

C

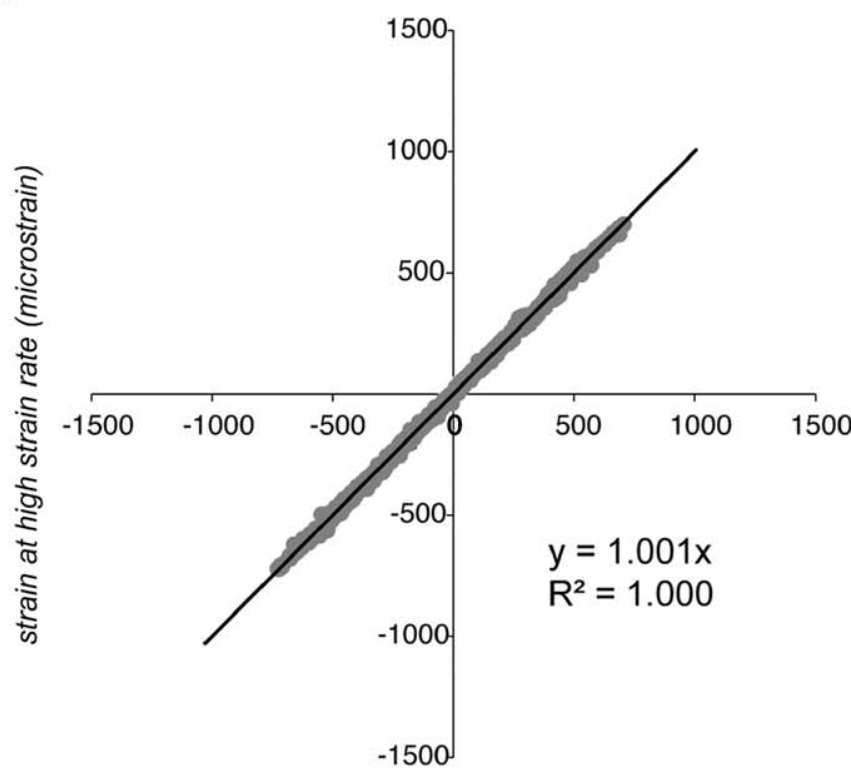

strain at low strain rate (microstrain)
The strain distribution was slightly affected by the loading rate (Fig. 8): strain was lower at a high-strain-rate in the proximal femoral metaphysis and diaphysis, while no significant difference was observed in the tibia and fibula (Table 4).

\subsection{Effect of loading direction}

Large differences existed between different loading configurations in terms of stiffness (Figs. 5-7) and strain distribution (Factorial ANOVA, $p<0.0005$, in all bone segments). This

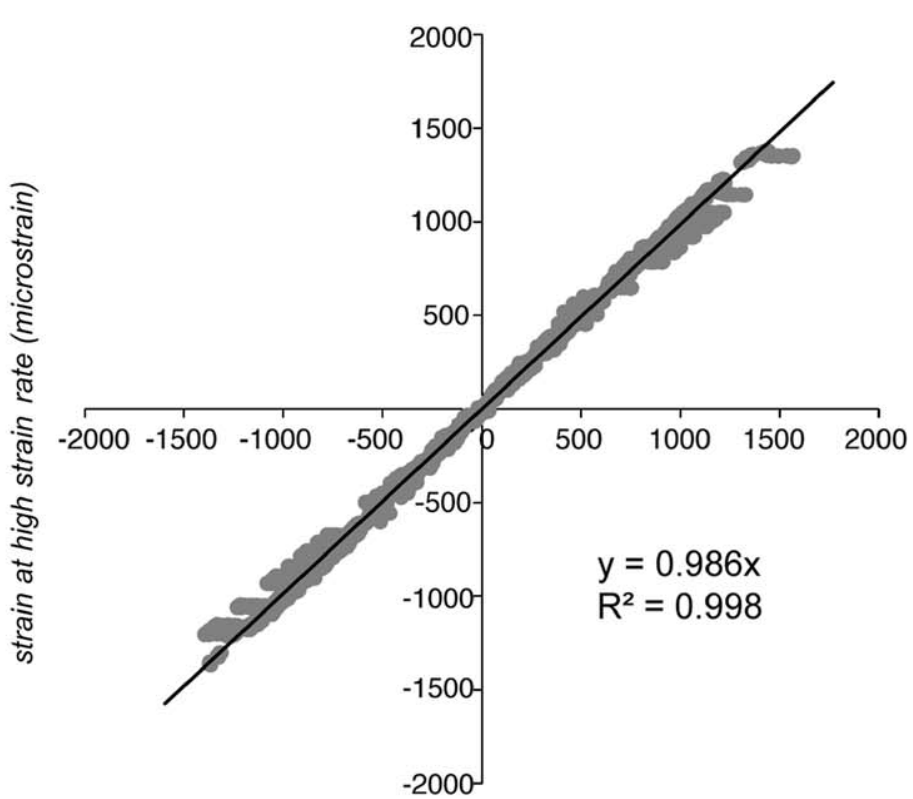

strain at low strain rate (microstrain)

d

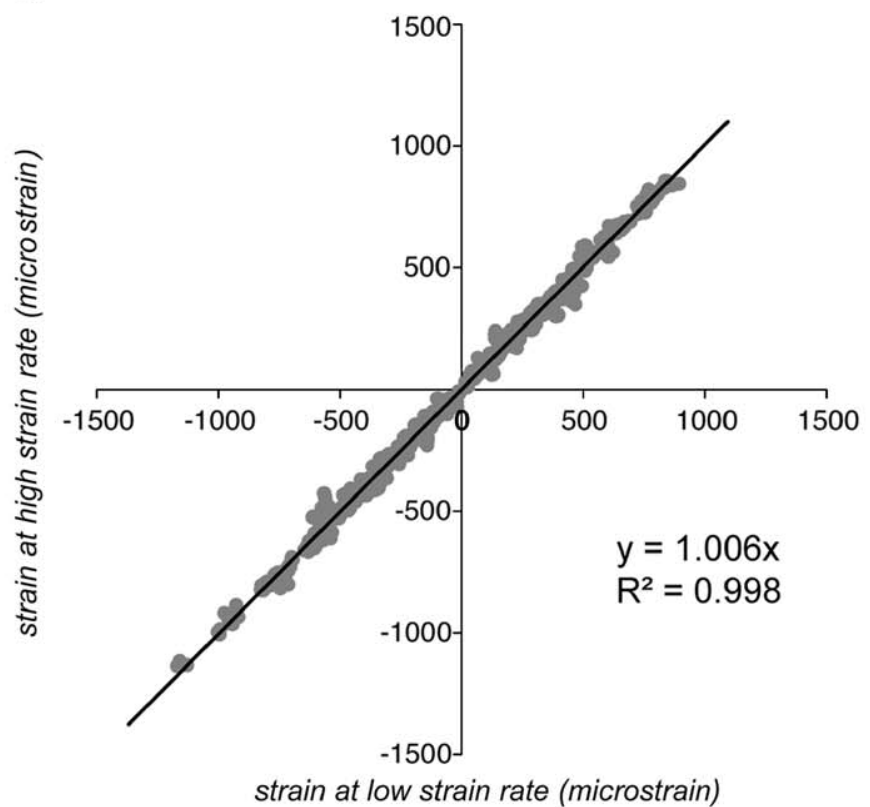

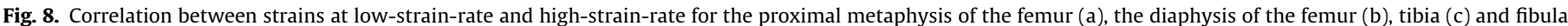

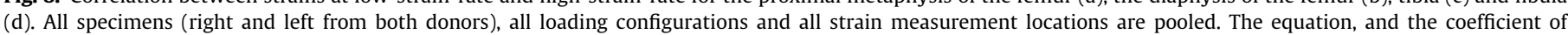

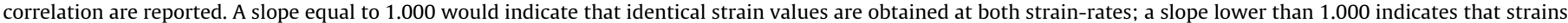
are lower when a higher strain-rate is applied (hence the bone behaves in a stiffer way). 
Table 5

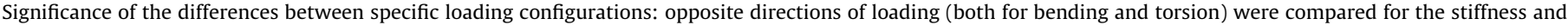
for the strain distribution.

\begin{tabular}{|c|c|c|c|}
\hline & Femur & Tibia & Fibula \\
\hline $\begin{array}{l}\text { Diaphysis: four-point- } \\
\text { bending in sagittal plane }\end{array}$ & $\begin{array}{l}3 \% \text { stiffer when anterior side in tension } \\
(p<0.0005) \\
\text { Different strain distributions for opposite } \\
\text { directions of bending }(p<0.0005)\end{array}$ & $\begin{array}{l}\text { 7\% stiffer when anterior side in tension } \\
(p<0.0005) \\
\text { Similar strain distribution for opposite } \\
\text { directions of bending }(p>0.5)\end{array}$ & $\begin{array}{l}3 \% \text { stiffer when posterior side in tension } \\
(p<0.001) \\
\text { Different strain distribution for opposite } \\
\text { directions of bending }(p<0.0005)\end{array}$ \\
\hline $\begin{array}{l}\text { Diaphysis: four-point- } \\
\text { bending in frontal plane }\end{array}$ & $\begin{array}{l}5 \% \text { stiffer when lateral side in tension } \\
(p<0.0005) \\
\text { Different strain distributions for opposite } \\
\text { directions of bending }(p<0.0005)\end{array}$ & $\begin{array}{l}11 \% \text { stiffer when medial side in tension } \\
(p<0.0005) \\
\text { Different strain distributions for opposite } \\
\text { directions of bending }(p<0.01)\end{array}$ & $\begin{array}{l}8 \% \text { stiffer when medial side in tension } \\
(p<0.02) \\
\text { Different strain distributions for opposite } \\
\text { directions of bending }(p<0.0005)\end{array}$ \\
\hline Diaphysis: torsion & $\begin{array}{l}15 \% \text { stiffer in intra-rotation than extra- } \\
\text { rotation }(p<0.0005) \\
\text { Similar strain distribution for opposite } \\
\text { directions of torsion }(p>0.5)\end{array}$ & $\begin{array}{l}5 \% \text { stiffer in intra-rotation than extra- } \\
\text { rotation }(p<0.005) \\
\text { Different strain distributions for opposite } \\
\text { directions of torsion }(p<0.0005)\end{array}$ & $\begin{array}{l}5 \% \text { stiffer in intra-rotation than extra- } \\
\text { rotation }(p<0.0005) \\
\text { Similar strain distribution for opposite } \\
\text { directions of torsion }(p>0.2)\end{array}$ \\
\hline
\end{tabular}

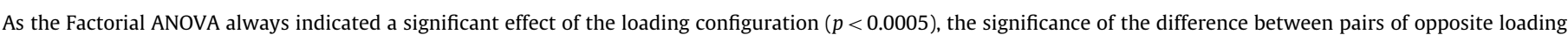

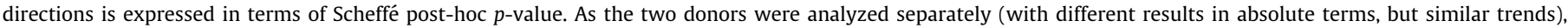
upper/lower bounds are reported for the $p$-values.

a

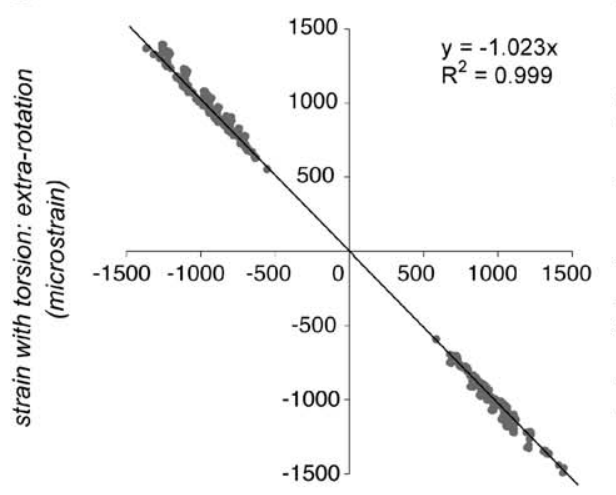

strain with torsion: intra-rotation (microstrain) b

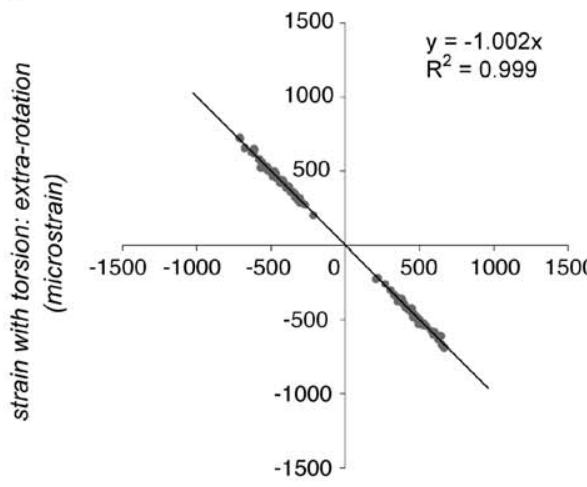

strain with torsion: intra-rotation (microstrain)
C

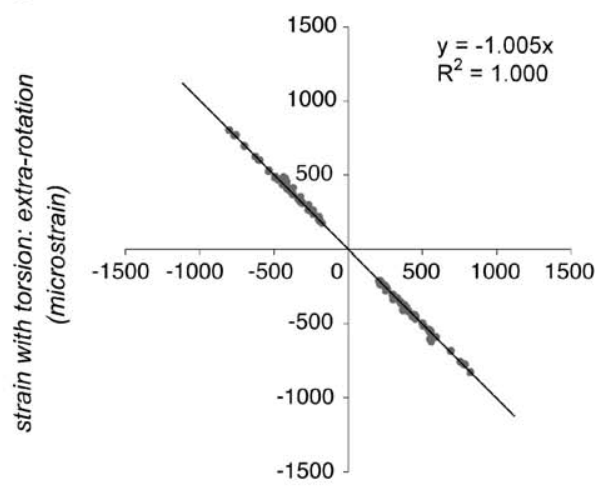

strain with torsion: intra-rotation (microstrain)

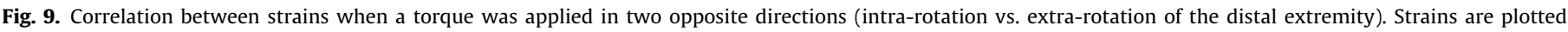

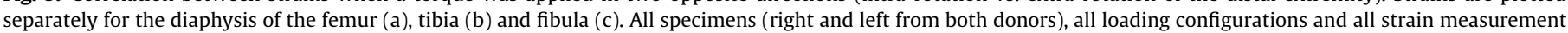

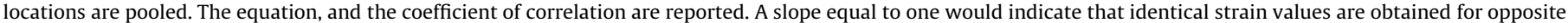

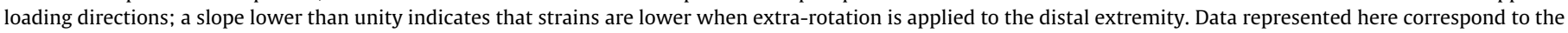
low-strain-rate (similar results were obtained at high-strain-rate).

difference was always statistically significant between different bending planes or between bending and torsion (Scheffé post-hoc, $p<0.005$ ). Significant differences existed (both in terms of structural stiffness and strain distribution) between opposite directions of bending in the same plane, and between opposite directions of torsion (Table 5). For instance, all bones were stiffer when loaded in intra-rotation than extra-rotation. In bending, the stiffer side varied between bones. Such differences were generally consistent between the two donors, and did not depend on the loading speed. As an example, the strain distributions for the two opposite directions of torsion are compared in Fig. 9: if the structure and the material behaved linearly, identical absolute strain would be obtained for both cases.

\section{Discussion}

Biomechanical factors such as the stiffness, strength and strain distribution of bones are key factors in determining bone formation and adaptation (Lanyon, 1980; Fung, 1990), osteoporosis (NIH, 2000) and fractures (Rockwood et al., 1991). Although stiffness and strength of lower limb bones have been investigated in the past, information is not complete. While the femur has been extensively investigated, little information is available about the strain distribution in the tibia, and the fibula has not been tested in vitro. In addition, past studies on lower limb bones focused on single bones, not on entire sets of bones from the same donors.

This study was designed to measure the stiffness and strain distribution of the different low limb bones from the same donors; to assess if there is any significant effect of viscoelasticity in whole bones within a physiological range of strain-rates; to assess if there is any difference in the behaviour in relation to opposite directions of bending and torsion.

Lower limb long bones (femurs, tibias and fibulas) from the same subjects were extensively tested and compared in vitro. The effect of viscoelasticity was visible in our tests, although quite moderate: minimal creep was measured while load was held, and a small difference was found in terms of structural stiffness and strain values, between high- and low-strain rate. When a significant effect was observed, the bones were stiffer at the high-strain-rate. This shows that in the range of physiological strain-rates (Bergmann et al., 2001, 2004), the effect of the loading speed does not affect the results dramatically. Significant differences existed between the stiffness and between the strain distributions measured when opposite direction of bending or torsion were applied. It is possible that such differences in terms 
of stiffness correspond to a similar difference in terms of strength. This suggests that bone structures not only are optimized for a given loading component (e.g. bending in a given plane), but also for a specific direction of bending within such plane.

The values found for the torsional stiffness of the femur and tibia (Figs. 5 and 6) are compatible with Martens et al. (1980): they found a stiffness of $9.81 \pm 2.88 \mathrm{Nm} /{ }^{\circ}$ for the femur, and $5.69 \pm 1.76 \mathrm{Nm} /{ }^{\circ}$ for the tibia (more in-depth comparisons are not possible as in that study specimens were unpaired, femurs and tibias were unmatched and the strain distribution was not measured).

Although controlateral bones are often used in comparative studies on surgical treatments, biomechanical differences between controlateral bones have been seldom quantitatively investigated. In a study on 54 pairs of femurs (Eckstein et al., 2004), a difference of $0.3-57 \%$ was found for the failure strength between right and left. A study on dogs (Markel et al., 1994) showed a difference of $8-35 \%$ for the stiffness of controlateral long bones. In a previous study on 12 pairs of proximal femurs (Cristofolini et al., 2009), we found a strain difference of $16-62 \%$ (depending on the strain measurement location) between controlateral specimens. The differences in the present study for the stiffness $(1-37 \%$ for the diaphysis of the femur, $7-18 \%$ for the tibia, $22-61 \%$ for the fibula) and strain (4-28\% for the diaphysis of the femur, $3-63 \%$ for the tibia, $1-67 \%$ for the fibula) are compatible with those studies.

The small creep observed here (few percent) and the small difference found between high- and low-strain rates are compatible with previous findings: Sasaki et al. (1993) reported that most creep takes place in few seconds, and accounts for $5-10 \%$ of the strain immediately after load application. Raftopoulos et al. (1993) observed that the Young modulus varied by only $10 \%$ when the strain-rate varied by 3 orders of magnitude. Also in cancellous bone viscoelasticity becomes obvious only at very low strain-rates (Guedes et al., 2006). In fact, in many cases viscoelasticity is neglected altogether (Carter and Spengler, 1978; Fung, 1980; Martens et al., 1983; Keaveny et al., 1994; Helgason et al., 2008), and (Cherraf-Schweyer et al., 2007) questioned the practical effects of viscoelasticity on a whole bone.

To our knowledge, the effect of opposite loading direction on whole bones has never been investigated. Thanks to the large number of strain gauges and repetitions available in the present study, and to the high repeatability of the test, small but in some case statistically significant differences were detected for opposite directions of loading, both in terms of stiffness and strain distribution (Table 5 and Fig. 9). As the theory of elasticity cannot explain such asymmetric behavior (Timoshenko and Goodier, 1982), such differences can only be explained by a non-symmetric behaviour of the bone tissue. In fact, bone exhibits a nonsymmetric behaviour, with a difference of several \% for the Young modulus in tension and compression (Reilly and Burstein, 1975; Fung, 1980).

This study was limited by the fact that only two donors were investigated. Such donors were selected as part of a larger EUfunded project addressing a multi-scale approach to the human skeleton. At all stages of the project, it was confirmed that such donors adequately represented typical elderly subjects (https:// www.biomedtown.org/biomed_town/LHDL/users/repository/; Viceconti et al., 2008). Including a larger number of donors in such an in-depth study would be extremely difficult. In fact, each region of each bone was instrumented with 8-32 triaxial strain gauges (over 600 grids were used in total); each bone was subjected to 6-12 different loading configurations. To our knowledge, no such a detailed study was ever performed on an entire series of bones from the lower limb.
The loading speed (and the consequent strain-rates) explored in this study were limited. Larger strain-rate ranges were explored in the past (Raftopoulos et al., 1993; Guedes et al., 2006). However, the scope of this study was not to assess if bones are viscoelastic in general, but to verify whether viscoelasticity does significantly affect the structural stiffness and the strain pattern within a physiological range.

Some differences were observed between controlateral specimens. It is unclear whether they are due to differences in terms of material properties, anatomical differences (or both). Further investigation is needed at different dimensional scales to elucidate donors' laterality (body-level), possibly different material properties (tissue-level) and composition (sub-tissue-level).

Another limitation relates to the fact that for some bones (e.g. tibia) the strong non-axisymmetry of the cross-section makes practical testing more difficult: a small alignment error (Conti et al., 2008) strongly affects the bending stiffness. This can explain why results for the tibia were somewhat less consistent.

In summary, an extensive biomechanical characterization of the long bones of the human lower limb was carried out. A number of different loading configurations were applied to the femur, tibia and fibula. Viscoelasticity did not have any pronounced effect in the physiological range of loading rates explored in this study. The stiffness and strain distribution varied greatly between bone segments, but also between directions of loading. Surprisingly, different stiffness and strain distributions were observed when opposite directions of torque or opposite directions of bending (in the same plane) were applied.

\section{Conflict of interest statement}

There is no potential conflict of interest: none of the Authors received or will receive direct or indirect benefits from third parties for the performance of this study. The only external source of funding was a grant by the European Community ("Living Human Digital Library_LHDL" grant IST-2004-026932, and "The Osteoporotic Virtual Physiological Human-VPHOP" grant FP7-ICT2008-223865).

\section{Acknowledgments}

The Authors wish to thank Fulvia Taddei, Enrico Schileo and Martino Pani for the stimulating discussions, Enrico Borgognoni, and Paolo Erani for contributing to the experiments, and Luigi Lena for the artwork. The European Community co-funded this study ("Living Human Digital Library_LHDL" grant IST-2004026932, and "The Osteoporotic Virtual Physiological HumanVPHOP” grant FP7-ICT2008-223865).

\section{Appendix A. Supplementary Material}

Supplementary data associated with this article can be found in the online version at doi:10.1016/j.jbiomech.2009.11.022.

\section{References}

Bayraktar, H.H., Morgan, E.F., Niebur, G.L., Morris, G.E., Keaveny, T.M., 2004. Elastic and yield properties of human trabecular and cortical bone. J. Biomech. 37, 2735 .

Bergmann, G., Heller, M., Graichen, F., Rohlmann, A., Strauss, J., Duda, G.N., 2001. Hip contact forces and gait patterns from routine activities. J. Biomech. 34, 859-871.

Bergmann, G., Graichen, F., Rohlmann, A., 2004. Hip contact forces during stumbling. Langenbeck's Arch. Surg. 389, 51-59. 
Carter, D.R., Spengler, D.M., 1978. Mechanical properties and composition of cortical bone. Clin. Orthop. Relat. Res. 135, 192-217.

Cherraf-Schweyer, C., Maurice, G., Taghite, M., Taous, K., 2007. An experimental and theoretical approach of elasticity and viscoelasticity of compact and spongy bone with periodic homogenization. Comput. Methods Biomech. Biomed. Eng. 10, 195-207.

Cody, D.D., Gross, G.J., Hou, F.J., Spencer, H.J., Fyhrie, D.P., 1999. Femoral strength is better predicted by finite element models than QCT and DXA. J. Biomech. 32, 1013-1020.

Conti, G., Cristofolini, L., Juszczyk, M., Viceconti, M., 2008. Comparison of three standard anatomical reference frames for the tibia-fibula complex. J. Biomech. 41, 3384-3389.

Cristofolini, L., 1997. A critical analysis of stress shielding evaluation of hip prostheses. Crit. Rev. Biomed. Eng. 25 (4 and 5), 409-483.

Cristofolini, L., Cappello, A., McNamara, B., Toni, A., 1996a. A minimal parametric model of the femur to describe axial elastic strain in response to loads. Med. Eng. Phys. 18, 502-514.

Cristofolini, L., Juszczyk, M., Taddei, F., Viceconti, M., 2007. In vitro replication of spontaneous fractures of the proximal human femur. J. Biomech. 40, 2837-2845.

Cristofolini, L., Juszczyk, M., Taddei, F., Viceconti, M., 2009. Strain distribution in the proximal human femoral metaphysis. Proc. Inst. Mech. Eng. [H] 223, 273-288.

Cristofolini, L., Viceconti, M., 2000. Mechanical validation of whole bone composite tibia models. J. Biomech. 33, 279-288.

Cristofolini, L., Viceconti, M., Cappello, A., Toni, A., 1996b. Mechanical validation of whole bone composite femur models. J. Biomech. 29, 525-535.

Eckstein, F., Wunderer, C., Boehm, H., Kuhn, V., Priemel, M., Link, T.M., Lochmüller E.-M., 2004. Reproducibility and side differences of mechanical tests for determining the structural strength of the proximal femur. J. Bone Miner. Res. 19, 379-385.

Fabeck, L., Tolley, M., Rooze, M., Burny, F., 2002. Theoretical study of the decrease in the femoral neck anteversion during growth. Cells Tissues Organs 171, 269-275.

Field, R.E., Rushton, N., 1989. Proximal femoral surface strain gauge analysis of a new epiphyseal prosthesis. J. Biomed. Eng. 11, 123-129.

Fung, Y.C., 1980. Bone and cartilage, Biomechanics-Mechanical Properties of Living Tissues. Springer Verlag, New York, pp. 383-415.

Fung, Y.C., 1990. In: Biomechanics: Motion, Flow, Stress, and Growth. Springer, New York.

Gray, H.A., Taddei, F., Zavatsky, A.B., Gill, H.S., 2008. Experimental validation of a finite element model of a human cadaveric tibia. J. Biomech. Eng. 130 pp 031016-11.

Guedes, R.M., Simoes, J.A., Morais, J.L., 2006. Viscoelastic behaviour and failure of bovine cancellous bone under constant strain rate. J. Biomech. 39, 49-60.

Heiner, A.D., Brown, T.D., 2001. Structural properties of a new design of composite replicate femurs and tibias. J. Biomech. 34, 773-781.

Helgason, B., Perilli, E., Schileo, E., Taddei, F., Viceconti, M., 2008. Relationships between bone density and mechanical properties: a review. Clin. Biomech. 23, 135-146.

Huiskes, R., Janssen, J.D., Sloof, T.J., 1981. A detailed comparison of experimental and theoretical stress-analyses of a human femur. In: Cowin, S.C. (Ed.) Mechanical Properties of Bone. A.S.M.E., New York, pp. 211-234.

Keaveny, T.M., Guo, X.E., McMahon, T.A., Hayes, W.C., 1994. Trabecular bone exhibits fully linear elastic behavior and yields at low strains. J. Biomech. 27 1127-1136.

Keyak, J.H., Kaneko, T.S., Tehranzadeh, J., Skinner, H.B., 2005. Predicting proximal femoral strength using structural engineering models. Clin. Orthop. Relat. Res., 219-228.
Lakes, R.S., Katz, J.L., 1979. Viscoelastic properties of wet cortical bone. III. A nonlinear constitutive equation. J. Biomech. 12, 689-698.

Lanyon, I.E., 1980. Bone remodelling, mechanical stress, and osteoporosis. In: De Luca, H.F. (Ed.), Osteoporosis. University Park Press, Baltimore, pp. 129-138.

Lochmüller, E.-M., Groll, O., Kuhn, V., Eckstein, F., 2002. Mechanical strength of the proximal femur as predicted from geometric and densitometric bone properties at the lower limb versus the distal radius. Bone 30, 207-216.

Markel, M.D., Sielman, E., Rapoff, A.J., Kohles, S.S., 1994. Mechanical properties of long bones in dogs. Am. J. Vet. Res. 55, 1178-1183.

Martens, M., Van Audekercke, R., De Meester, P., Mulier, J.C., 1986. Mechanical behaviour of femoral bones in bending loading. J. Biomech. 19, 443-454.

Martens, M., VanAudekercke, R., Delport, P., De Meester, P., Mulier, J.C., 1983. The mechanical characteristics of cancellous bone at the upper femur. J. Biomech. 16, 971-983.

Martens, M., van Audekerke, R., de Meester, P., Mulier, J.C., 1980. The mechanical characteristics of the long bones of the lower extremity in torsion. J. Biomech. 13, 667-676.

$\mathrm{NIH}, 2000$. Consensus Statement on Osteoporosis Prevention, Diagnosis, and Therapy. NIH Consensus Statement Online, US Department of Health and Human Services, National Institute of Health, 2000 March 27-29. vol. 17(1), pp. 1-36.

Ohman, C., Dall'Ara, E., Baleani, M., Van Sint Jan, S., Viceconti, M., 2008. The effects of embalming using a $4 \%$ formalin solution on the compressive mechanical properties of human cortical bone. Clin. Biomech. (Bristol, Avon) 23, 1294-1298.

Raftopoulos, D., Katsamanis, E., Saul, F. Liu, W., Saddemi, S. 1993. An intermediate loading rate technique for the determination of mechanical properties of human femoral cortical bone. J. Biomed. Eng. 15, 60-66.

Raftopoulos, D.D., Qassem, W., 1987. Three-dimensional curved beam stress analysis of the human femur. J. Biomed. Eng. 9, 356-366.

Reilly, D.T., Burstein, A.H., 1975. The elastic and ultimate properties of compact bone tissue. J. Biomech. 8, 393-405.

Rockwood, C.A.J., Green, D.P., Bucholz, R.W., 1991. In: Rockwood and Green's Fractures in Adults. J.B. Lippincott, Philadelphia.

Sasaki, N., Nakayama, Y., Yoshikawa, M., Enyo, A., 1993. Stress relaxation function of bone and bone collagen. J. Biomech. 26, 1369-1376.

Schileo, E., Taddei, F., Cristofolini, L., Viceconti, M., 2008. Subject-specific finite element models implementing a maximum principal strain criterion are able to estimate failure risk and fracture location on human femurs tested in vitro. J. Biomech. 41, 356-367.

Schileo, E., Taddei, F., Malandrino, A., Cristofolini, L., Viceconti, M., 2007. Subjectspecific finite element models can accurately predict strain levels in long bones. J. Biomech. 40, 2982-2989.

Taddei, F., Cristofolini, L., Martelli, S., Gill, H.S., Viceconti, M., 2006. Subject-specific finite element models of long bones: an in vitro evaluation of the overall accuracy. J. Biomech. 39, 2457-2467.

Timoshenko, P.S., Goodier, J.N., 1982. In: Theory of Elasticity. Mc Graw Hill, New York.

Toridis, T.G., 1969. Stress analysis of the femur. J. Biomech. 2, 163-174.

Viceconti, M., Taddei, F., Van Sint Jan, S., Leardini, A., Cristofolini, L., Stea, S., Baruffaldi, F., Baleani, M., 2008. Multiscale modelling of the skeleton for the prediction of the risk of fracture. Clin. Biomech. (Bristol, Avon).

Yang, K.-H.-., Shen, K.L., Demetropoulos, C.K., King, A.I., Kolodziej, P., Levine, R.S., Fitzgerald, R.H.J., 1996. The relationship between loading conditions and fracture patterns of the proximal femur. J. Biomech. Eng. 118, 575-578. 